and none better can be had than the aromatics used in sal volatile-namely, the oil of lemons and the volatile oil of nutmegs. It is useful also to colour the fluids slightly, so that they may be at once recognised, and mistakes for chloroform prevented. But I must very carefully recommend the operator to make sure that he is using pure absolute ether and absolute alcohol, perfectly free from the abominable contamination of methyl and its compounds. By care in this respect he will secure constant uniformity in his operations, and avoid the ill effects of those adulterations to which alcohol and ether are too subject. It is also important to observe that the ether and alcohol are really absolute. For this purpose the ether should be washed in distilled water, and then drawn off by a waterbath. The strongest commercial alcohol should also be procured and redistilled from chloride of calcium, drawing off three-fourths of the amount held by the still. The advantages are these, that definite fluids of known strength are employed, the results of the use of which will always be comparable with each other, and the inhaler does not become charged with water or the heavier parts of the spirit. By proceeding thus, a highly stimulating, easily vaporisable, and a very agreeably smelling spirit is obtained - very different from the ether and alcohol of the shops.

The question will be asked as to the value of using these anæsthetics in a separate form, when all can be had combined in the mixtures so strongly recommended by the Chloroform Committee. The principal and most important advantages are these : that we thus isolate and have under our control a perfectly safe stimulant and mild anæsthetic, while in the same instrument we have at command a most valued and powerful agent for the abolition of pain. And these are capable of being so united and blended together in any desired quantities as to give us such control over the individual case operated on as that may seem to require. We are able to produce any degree of anæsthesia by this means, from the slight dreamy unconsciousness to the deepest coma; and by aid of the index we can at any moment observe what is the precise amount of either or of both agents which is being employed. Anæsthesia may, in fact, be procured more quickly than by any of the anæsthetic mixtures, and it may then be graduated to the varying condition of the individual-in the paroxysm of labour pain and in the interval of comparative freedom, in the division of skin and sensitive structures and in the dissection of less nerve-endowed parts. Another and most important advantage is, that whereas anæsthetic mixtures all vary in composition by prolonged employment, and clog the instrument with unevaporated heavy fluid, no such effect occurs in this method.

For the mouth-piece I employ Snow's, or any other with a similar valve arrangement. The part of my instrument which is peculiar is the receptacle for chloroform and the corresponding one for the alcohol and ether. This part consists of two separate pieces, an upper and a lower (Figs. 1 and 2); the

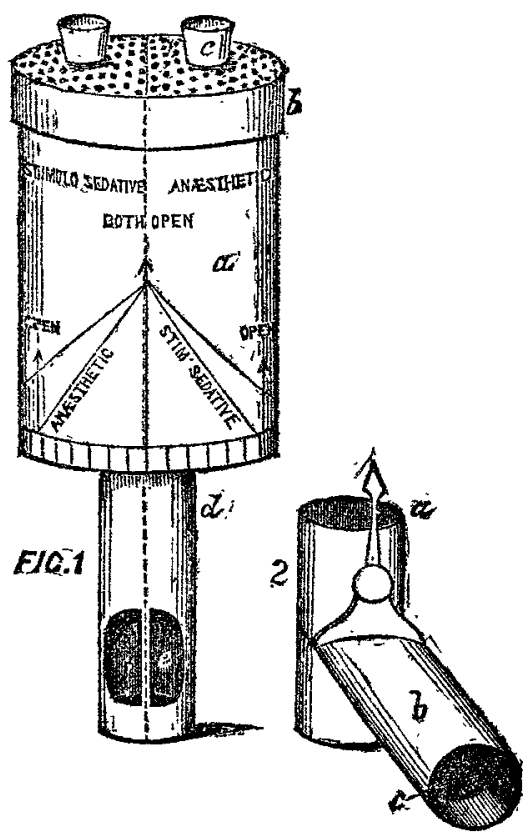

apper fitting as in a socket into the vertical part of the lower tabe. The upper part consists of a tube $(a)$ of a little more than two inches diameter, and is three in height. It is fitted with a perforated lid (b), at each side of which is a small funnel $(c)$. This tube is divided through its whole length by a metal diaphragm $(e)$, which also runs down into the smaller tube fitted into it at the bottom. The whole forms one compact piece from top to bottom, and enclosing two entirely distinct spaces, one of which is reserved for the chloroform, and the other for the alcohol and ether. These have no communication with each other, but have a common opening of an elliptical figure at the bottom $(e)$ of the smaller tube. This smaller tube $(d)$ is accurately fitted, so as to work easily round in the vertical piece of the other part (Fig. 2) of the instrument. In so doing it necessarily exposes, according to the direction in which the larger tube is turned, first one side of the opening (say that leading to the alcohol and ether compartment), and then the other, leading to the chloroform. It is thus seen that we can perfectly control the nature of the vapour allowed to pass into the other part of the instrument, according as we cause it to turn to the right or to the left.

The second part (Fig. 2) of my instrument forms the receptacle for the socket $(a)$ of the tinst, and carries the vapour up to the mouth-piece. But in order thoroughly to mix the separate vapours before they are breathed, a piece $(c)$ of perforated gilt metal is fixed inside the horizontal arm $(b)$ of this piece, and the diffusion thus caused effects a complete mixture before the vapours rise to the mouth. This same horizontal arm carries the index-finger, which points to the scale engraved at the upper part of the receptacle, and by its means (the scale having been carefully adjusted by experiment to the openings below) the quantity and the quality of the vapour are at once read off. What is told by this scale is represented below in the diagram. The rise of the lines exhibits the gradual increase of aperture. The graduated marks answer the double purpose of an index and a safeguard; for the index-finger fits into them with a spring, and holds the apparatus at the required degree until it be desirable to shift it farther. The instrument may thus be consigned to a nurse for a time, and the operator fee secure that no excess of chloroform can be accidentally administered.

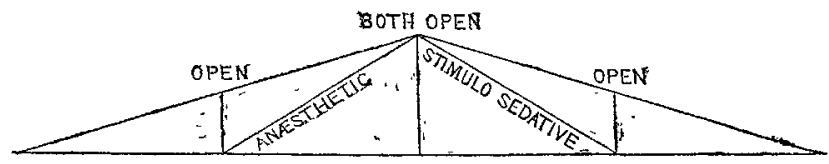

I may add, that Mr. Blaise (of Messrs. Savigny's) has taken great interest in this instrument, and has produced an apparatus from my designs most complete in its parts, and, as I have publicly proved at one of our great hospitals, most successful in operation.

In actual practice the instrument is more simple and handy to use than could be believed from this account; and it will be no little pleasure to me if, in its adoption, life be saved while suffering is abolished.

Sloane-street, January, 1866.

\section{MULBERRY CALCULUS OF LARGE SIZE REMOVED FROM THE FEMALE BLADDER BY LITHOTRITY.}

\section{GOOD RECOYERY.}

BY CHRISTOPHER HEATH, Esq., F.R.C.S., ASSISTANT-SURGEON TO THE WESTMIINSTER HOSPITAL.

THE occurrence of calculus in the female bladder is rare as compared with the male; and the existence of a mulberry calculus in the female is so uncommon as to lead me to record the folluwing case of the kind. Most surgeons are agreed as to the propriety of applying lithotrity to calculus in the female when the condition of the urinary organs and the nature and size of the calculus do not forbid the operation.

In The LaNCer for October 1ith, 1862, is a series of three cases of stone in the female, occurring in the practice of Sir William Fergusson, which is very instructive, since each case serves to illustrate different modes of treatment, and two of them, curiously, were instances of mulberry calculus. In one case a mulberry stone was extracted through an incision into the vagina, which was immediately closed with sutures, but unfortunately resulted in a vesico-vaginal fistula; in the second, the mulberry calculus was so excessively hard as to defy litho- 
trity, and it was therefore extracted by dividing the urethra, with consequent slight incontinence; in the third case, a uricacid stone was successfully crushed and brought away, with perfectly satisfactory results.

When first called to my patient, and upon understanding that she had been submitted to the operation of lithotrity two years previously, I anticipated finding only a small stonesome fragment of the former calculus which had escaped detection-and was therefore prepared to extract it by rapid dilatation of the urethra, as recommended by Mr. Bryant; but upon ascertaining the size of the stone this idea was necessarily abandoned, and I had immediate recourse to the operation of lithotrity.

On the 28th of October, 1865, I met Mr. Garnsey, of Stoke Newington, in consultation, to examine Miss M. O-_ aged thirty-two, who was suffering from all the symptoms of return of stone, for which lithotrity had been performed two years previously. On the former occasion there had been but two performances of the operation, and she had passed small quantities of phosphatic stone after them. The operator considered her to be cured, but she had never been perfectly easy since, and latterly the bladder symptoms had been much aggravated.

Chloroform having been administered, I sounded the bladder, and immediately found a calculus. I therefore dilated the urethra with the forefinger insinuated along a director, and grasped the calculus with forceps, intending to extract it. This, however, I found immediately would be impossible without lacerating and distending the parts so as to lead almost inevitably to incontinence, and I therefore disengaged the forceps, and introduced a lithotrite. On grasping the stone in the lithotrite it measured an inch and a quarter. I crushed it three times, and then broke up some of the débris, which came away on washing out the bladder. Ordered to take fifteen minims of chlorodyne immediately, and to repeat at bedtime, and to have the bladder washed out with tepid water daily.

Nov. 2nd.-I found the patient very comfortable. She had passed a large quantity of débris, more, she thinks, than she did altogether after the former operations. These pieces are evidently the outer layers of a phosphatic calculus. She has kept to the sofa, and has suffered little inconvenience except on one occasion, when a fragment became fixed in the urethra, and was extracted by Mr. Garnsey. I introduced the lithotrite under chloroform, and canght the stone, which was still an inch in diameter. I crushed this twice, and then found an excessively hard nucleus, which required very considerable force to break it.

6th.-Has passed a large number of fragments since the last operation, and one of them very large and rough, consisting apparently of oxalate of lime coated with phosphates. Under chloroform I caught and broke twice a very large and hard fragment, and then with the lithotrite extracted three large rough pieces and two smaller ones, leaving the bladder apparently free of all large pieces. There was more difficulty on this occasion than before in keeping water in the bladder during the operation, and it was necessary to inject warm water three times.

9th.-Has passed only one fragment, and was in a good deal of pain this morning. Under chloroform I caught a large fragment, but it slipped from the lithotrite twice on attempting to extract it. I therefore withdrew the lithotrite, and caught the piece with small forceps, and extracted a very large and irregular fragment of oxalate of line. Very careful examination with the bladder injected failed to detect any more stone.

22nd. - Visit delayed until to-day on account of menstruation. Has been very comfortable until the last day or two, when there has been some irritability of the bladder. No fragments have passed. On sounding carefully with the lithotrite, I detected a small fragment, which I extracted. On reintroducing the lithotrite, it came against a fragment near the neck of the bladder, which slipped from the instrument. The bladder was now forcibly emptied by the violent expulsive efforts of the patient, and, finding the piece just within the urethra, I extracted it with small forceps. It proved to be a good-sized piece of phosphatic matter. The bladder was now re-injected, and the most careful examination failed to detect any more fragments. The patient was ordered to take dilute nitro-muriatic acid in decoction of pareira for a month, and to have the bladder washed out occasionally.

Jan. 13th, 1866. - Mr. Garnsey writes that Miss $\mathrm{O}$ - is quite free from pain of any kind, and is able to resume her ordinary habits. She has increased considerably in weight since the operation.

The weight of the collected fragments of stone was 245 grs., equal to 4 dr. 5 grs. The analysis was kindly made for me by
Dr. Dupré, who found the larger pieces to consist of oxalate of lime, and the smaller external portion to be phosphate of lime and triple phosphate. No trace of uric acid was to be found.

Remarks. - The above cannot be considered as a case of recurrence of stone, for it is evident, from the nature of the calculus and the history of the case, that the former operation had not been successful in ridding the patient of more than the outer coating of the calculus. I was fortunate in being able to break the mulberry nucleus satisfactorily, though not without considerable effort; and the previous dilatation of the urethra facilitated the extraction of the fragments, so that the bladder was soon relieved of their irritating presence. It was necessary on each occasion of operating to inject warm water after the bladder had emptied itself in the progress of the operation, and on some occasions this had to be done more than once, but was readily accomplished with an india-rubber bottle and catheter, without materially impeding or lengthening the proceeding.

Cavendish-place, Jan. 1866.

\section{d atthriror}

OF THE PRACTICE OF

\section{MEDICINE AND SURGERY} IN THE

\section{HOSPITALS OF LONDON.}

Nulla autem est alia pro certo noscendi via, nisi quamplurimas et morborum et dissectionum historias, tum aliorum, tum proprias collectas habere, et inte se comparare.-MorgagNI De Sed. et Caus. Morb., lib. iv. Procemium.

\section{GUY'S HOSPITAL.}

ELEPHANTIASIS OF THE LEFT LEQ; LIGATURE OF THE EXTERNAL ILIAC ARTERY.

(Under the care of Mr. BRYANT.)

SEvERAL cases of that form of elephantiasis which has beer styled Elephas pachydermia, Barbadoes leg, or the elephantiasis of the Arabs ("Holmes's Surgery," vol. iv., p. 755), have been lately under observation at some of the hospitals. The disease, as is well known, is rare in Europe, though common enough in the West Indies, the islands in the Pacific Ocean, and Cochin in Madras. In Otaheite, where it is particularly frequent, it is called by the natives féfé, and has been attributed to the sudden alternations of temperature to which they are subjected, especially by frequently going in and out of the water. In the cases before us, however, neither this nor any other invariable antecedent was present, and it must be acknowledged that the etiology of the disease is very obscure. Nor is its pathology much more satisfactorily understood. It is most evidently characterized by hypertrophy of the skin and of the subcutaneous areolar tissue. The limb becomes so much enlarged as to be a great encumbrance to the patient. In some cases this enlargement is the main source of discomfort. In others-and this is most frequently the case-the skin is covered with large patches of warty-looking protuberances, discharging an offensive fluid. Occasionally, too, the skin bursts, giving exit to a discharge of similar character. The glands often suppurate, and the lymphatics are felt as hard, nodulated cords. Dr. Carnochan, of New York, describes a dilated state of the main arterial trunk. The disease does not seem to interfere much with the general health, and many of these patients carry their burthen for years, suffering immense in. convenience, but little or no pain. When pressure, frictions, and iodine fail to produce absorption, the general resource has been to amputate the limb; and this proceeding meets with success notwithstanding the fatty condition of the muscular structure which accompanies or results from the disease. Nor does it appear, according to Mr. Fiddes, of Jamaica, that the arteries of the limb are in any way indisposed to adhesive closure, though they probably participate to some extent in a similar fatty transformation. Mr. Fiddes remarks that twenty years ago there existed in Jamaica the greatest dread of surgical interference with elephantiasis of the leg, from a belief 